\title{
Geotechnical Engineering Slope Monitoring Based on Internet of Things
}

\author{
https://doi.org/10.3991/ijoe.v14i06.8706 \\ Xiaobing Hou \\ Anyang Institute of Technology, Anyang, China \\ $\mathrm{hxb} 200918$ @163. com
}

\begin{abstract}
To improve the monitoring system of rock and soil engineering slope, based on the technology of Internet of things, the monitoring of rock and soil slope was studied. A multi parameter remote monitoring system based on the technology of Internet of things was proposed. By combining GPS locator with several sensor instruments, many parameters, such as ground displacement, deep displacement, groundwater level, stress and strain, were collected. Through the Internet of things technology, the key data were transmitted to the monitoring room. The wireless transmission of the monitoring data was completed. Using information fusion technology, database management and Web service, the monitoring data were classified and managed. Through the data analysis, the reliability theory was used to predict the slope. Finally, the rock and soil engineering slope monitoring based on the Internet of things was verified. The results showed that the stability of the slope was influenced by many factors. At the same time, the effectiveness and accuracy of monitoring data were important for slope prediction. To sum up, the reliability theory is more suitable for the stability analysis of the local slope and the section.
\end{abstract}

Keywords-Internet of things, geotechnical engineering, slope monitoring

\section{Introduction}

In recent years, with the development of information technology, the technology of Internet of things has been applied to the construction of mine. In order to ensure the safety of geotechnical engineering process, slope displacement and groundwater level need to be monitored. The traditional monitoring is mainly to read the data through the sensor. In the form of report, the safety condition of the slope is obtained. This method cannot collect information in time, and it cannot meet the requirement of continuous monitoring. While summarizing the information, it is impossible to feed back the real situation of the slope in time.

In the field of engineering, any items are connected to the Internet through information sensing devices. Information is exchanged for intelligent identification, location tracking, monitoring, and management. With the development of the technology of the Internet of things, it is gradually used in slope monitoring. The instability and failure of the slope is a process from a gradual change to a catastrophe. Generally, all 
landslides have a precursor. For the high steep rock slope, the mechanical parameters and the stable state of the rock and soil cannot be determined. It is difficult to accurately predict through human intuition and experience. The sensor can capture the abnormal information of the slope stability before the landslide occurs, so as to predict the danger in time and avoid the loss of personnel and equipment. Therefore, based on the Internet of things technology, geotechnical slope monitoring system can effectively solve many problems at present.

\section{State of the art}

At present, Internet of things technology is widely applied in various fields and it is more and more important in geological engineering monitoring field. Smethurst, J. A. et al. [1] discussed the current role of instrumentation and monitoring, including the reasons for monitoring infrastructure slopes, the instrumentation typically installed and parameters measured. And they investigated recent developments in technology and considered how these may change the way that monitoring is used in the future. Srivastava [2] demonstrated the approach for spatial variation modeling of geotechnical parameters and reliability analysis based stability assessment of highly weathered rock slope. He proved that numerical modeling of spatially varying geotechnical parameters gave more realistic treatment to the property variation of a natural material and stability assessment. Ulusay, R. et al. [3] connected a two-year collaborative program of geotechnical and hydrogeological investigations throughout the current pit and the area in the direction of advance of the pit in accordance with laboratory tests and analyses. Aly, H. et al. [4] showed the study of Internet of things and big data mainly from two aspects: discussion of big data on Internet of things and how it is created. They also discussed the challenges and techniques that solve these issues and observed the architecture of Internet of things.

In domestic, there were also a large amount of researches on Internet of things. Du and Wang [5] explored the Newmark displacement model and applied it for analyzing the probabilistic seismic slope displacement hazard. Lin and others [6] focused on the Zigbee-based Internet of Things (IoTs) in 3D terrains. They proposed a novel simulation model for IoT and investigated the effects of various terrains, node's mobility and traffic loads. Rui [7] put forward the application framework for early warning service for dealing with geological disaster warning, which was one of the applications of Internet of things. He also used the firewall and authentication technology, to deal with the early warning information safety requirements. Guo and others [8] attempted to apply the Internet of Things (IoT) technology in the development of the smart tourism industry and smart tourism cities, which showed us the wide application of Internet of things. Sun et al. [9] discussed a tailings dam monitoring and prealarm system (TDMPAS) based on the internet of things (IOT) and cloud computing combined with the abilities of real-time monitoring of the saturated line. Zheng et al. [10] constructed the mixed kernel by a typical local kernel-radial basis function (RBF) and a typical global kernel-polynomial kernel and proved that the Internet of things had real application value in predicting deformations of slope. Li et al. [11] 
developed a novel approach for predicting slope displacement combining mathematical morphology (MM), nonparametric and nonlinear model, so as to improve the prediction accuracy. And they designed a parallel-composed morphological filter with multiple structure elements to process measured displacement time series with adaptive multi-scale decoupling.

In summary, the Internet of things technology is introduced from its application and combination with other technologies. The slop monitoring is also discussed from slope displacement, slope deformation and so on. However, the above researches do not combine the Internet of things technology in slope monitoring in geological engineering and the effectiveness and precision of slope monitoring are low. Aiming at improving the monitoring system of rock and soil engineering slope, based on the technology of Internet of things, the monitoring of rock and soil slope is studied. A multi-parameter remote monitoring system based on the technology of Internet of things is proposed and the wireless transmission of the monitoring data is completed. Using information fusion technology, database management and Web service, the monitoring data are classified and managed. Through the data analysis, the reliability theory is used to predict the slope. At last, the effectiveness and accuracy of monitoring data are improved by the Internet of things technology, which has the advantage of high practical value.

\section{$3 \quad$ Methodology}

\subsection{Multi-parameter remote monitoring method}

To play a real monitoring and forecasting effect on unstable slope, a multiparameter monitoring method is needed. Based on the above ideas, the combination of several monitoring techniques is proposed. A comprehensive monitoring system based on GPS monitoring is established, which is supplemented by sensor monitoring. This multi-parameter remote monitoring system can monitor various characteristics parameters of unstable landslide in large scale before it collapses in various aspects, thus obtaining valuable preparation time for engineers. According to the different characteristics of the slope, different parameters can be combined and different types of sensors are selected. Then, the data is transmitted to a remote-control room by wireless communication technology. In the control room, the correct conclusions are given through the system data analysis system and the expert's experience analysis, which can play a real role in prediction and prediction. The field monitoring model is improved on the basis of the RSM-24FD engineering tester. The multi parameter structure diagram of the monitoring is shown in Figure 1. 


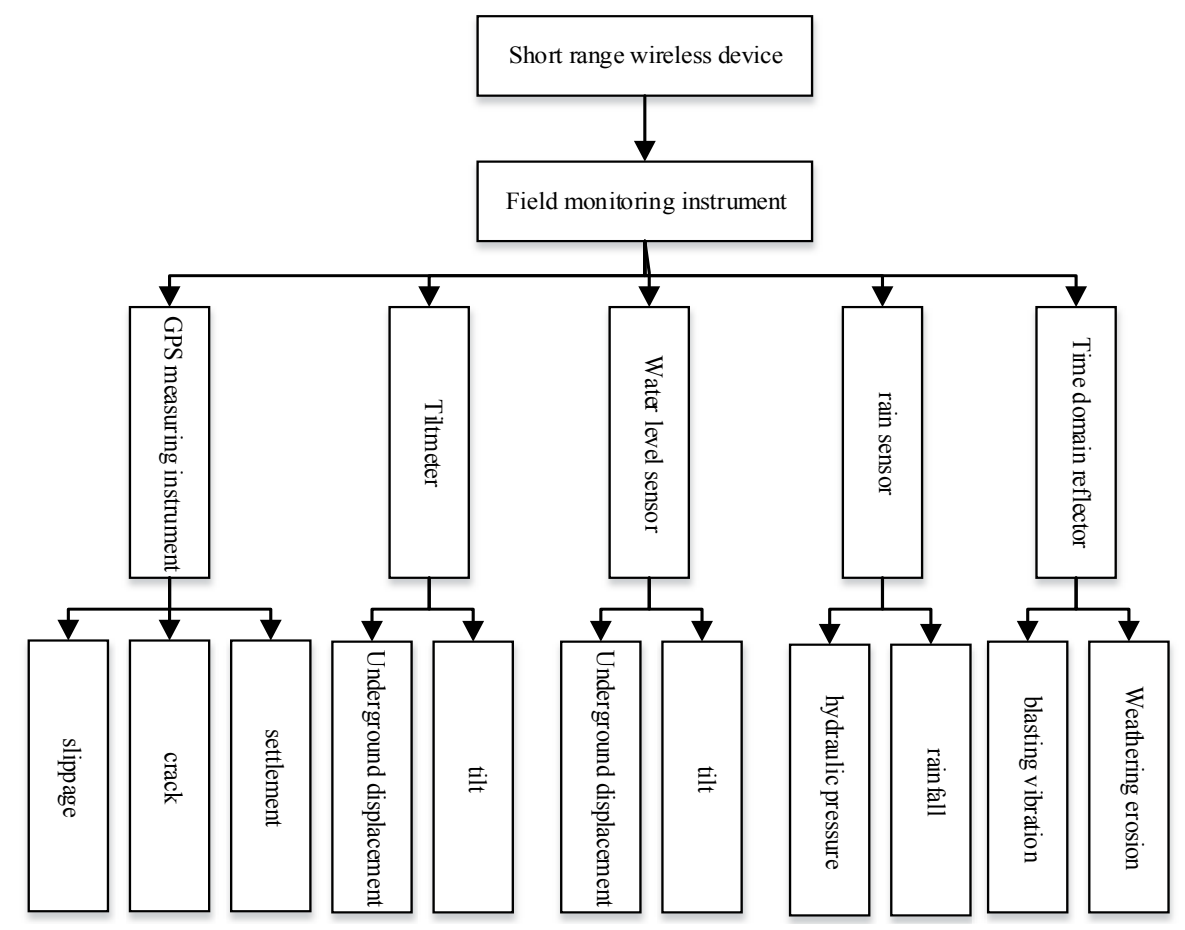

Fig. 1. Structure of multi parameter monitoring instrument

\subsection{Management of slope monitoring data in geotechnical engineering}

The monitoring data are transmitted to the remote monitoring information control center through the ZigBee technology. A large-scale slope monitoring information management system is set up. They manage the database of the ground and deep displacement, the database of the water level change attribute and the attribute database of the stress and strain change. Through Internet technology, the staff can call and view the data in each database.

In order to facilitate users to manage the application, connection, device and other contents of the intermediate service components of the Internet of things, a Web service system based on Internet is developed. At the same time, it will package and open the interface of wireless sensor network, which is convenient for users to call on the Internet. This is also an example of wireless sensor network joining the Internet. The relationship between Web services, middleware, and wireless sensor networks is shown in Figure 2.

As shown in Figure 2, the Web service background interacts with the middleware through two TCP connections. The data transmission of wireless sensor network and the management of middleware are realized respectively. The Access database stores the information of the equipment, the application information and so on. The wireless sensor network data interface (API) packages the wireless sensor data into the interface and provides the call to the user. 


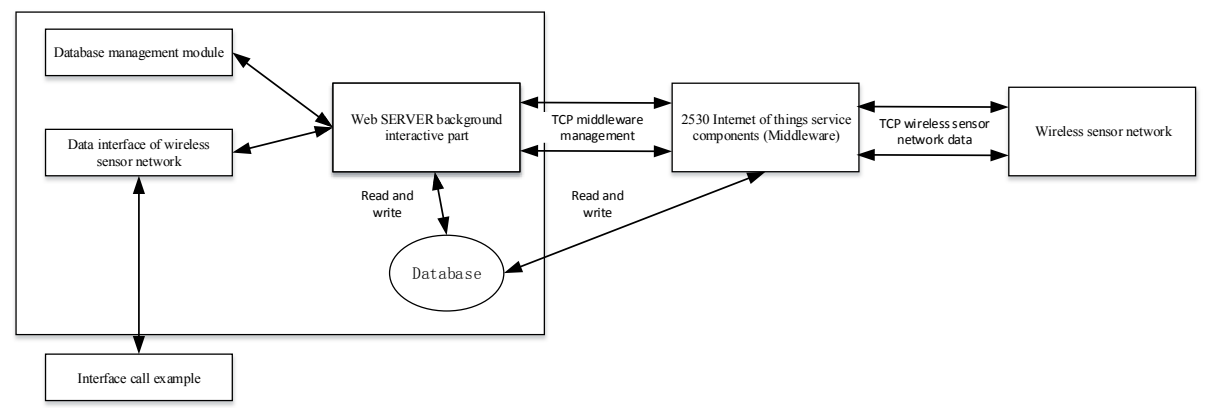

Fig. 2. The relationship between wireless sensor network and Web service

\subsection{An empirical analysis of rock and soil engineering slope monitoring based on the technology of Internet of things}

Before evaluating the stability of the slope, the most important prerequisite is to get the detailed geological data of the slope, including some important parameters, such as lithology, geological structure of the rock mass, joint fracture, elastic modulus of rock and so on. However, the mechanical properties of rock will change with the change of environment. The mechanical properties of rock may change greatly in different time and space. Based on this, a slope uncertainty analysis method based on reliability theory is proposed. The numerical calculation method is combined with the statistical theory to evaluate the stability of the slope.

The first is the geological survey. The geotechnical engineering selection in this paper is almost the east-west direction. Due to the difference of paleo sedimentary environment and material composition, there is obvious phase transition between some strata along the strike and tendency. There are faults, fractured zones and weak structural planes in the northern slope, which makes the stability of the upper slope very poor. The natural slope of the southern slope is steeper. The maximum height difference of the slope in the mining area reaches $600 \mathrm{~m}$, which belongs to the high and steep slope. The bottom of the geotechnical project is marked $+840 \mathrm{~m}$, the maximum elevation is $+1503 \mathrm{~m}$, the height difference is $663 \mathrm{~m}$, and the final slope angle is between $39^{\circ} \sim 41^{\circ}$. The slope rock mass is mainly biotite andesite, chlorite schist and kaolinite. The rock is loose and broken, the degree is different, and the weathering cracks are developed, and the stability is poor. The slope body has a more developed joint surface, and it is easy to slide in the form of conglomerate.

Furthermore, the geometric model of slope numerical calculation is analyzed. The slope model is established by selecting the geometric parameters at the $+1044 \mathrm{~m} \sim+1056 \mathrm{~m}$ section at the section. The step height is $\mathrm{H}=12 \mathrm{~m}$, the slope length is $20 \mathrm{~m}$, and the slope angle is $41^{\circ}$. The bottom border to the bottom of the slope is $2 \mathrm{~m}$. The top of the hill to the right of the boundary is $8 \mathrm{~m}$. When FLAC3D is used for numerical solution, there are two assumptions: first, the length of the Y direction is a unit length, and the velocity of all the points in the $\mathrm{Y}$ direction in the model is constrained. The problem of solving the model is a plane strain problem. Second, the rock mass in the model is isotropic homogeneous rock mass. 
Then, the uncertainty analysis based on reliability is introduced in detail. The first is the Latin Hypercube Sampling Monte Carlo Simulation (LHSMCS). Monte Carlo simulation is a numerical calculation method of calculating the probability $\mathrm{P}$ of a sample by sampling a random sample in the matrix through a computer. According to the definition of sub-sample, the probability that random event $A$ occurs is $P_{0}$. In $N$ repeated tests, if the number of occurrences $\mathrm{A}$ is $\mathrm{M}$, then by the law of large numbers, when $\mathrm{N}$ is large enough $(N \rightarrow \infty), 1 / n \sum X_{k}(k=1,2,3 \ldots N)$ is converged to $1 / n \sum E X_{k}(k=1,2,3 \ldots N)$. The frequency $M / N$ converges to $\mathrm{P}_{0}$. The mechanical properties of rock are an uncertain factor. The cohesion $\mathrm{c}$ and the internal friction angle $\alpha$ are regarded as two random variables. Its probability distribution is subject to normal distribution. The Matlab7.11.0 (R2012b) library function rand (0,1) is used to select the different $\mathrm{c}$ values and $\alpha\left(c_{1}, a_{1}\right),\left(c_{2}, a_{2}\right), \ldots,\left(c_{n}, a_{n}\right)$ values of the $\mathrm{N}$ group. The different sample values of this $\mathrm{N}$ group are evenly distributed in $[0,1 / N],[1 / N, 2 / N], \ldots,[N-1 / N, 1]$. The calculation of the slope safety factor of $\mathrm{N}=10, \mathrm{~N}=100$ and $\mathrm{N}=1000$ is simulated respectively. The Monte Carlo simulation principle is very simple. The concept is clear. The simulation calculation can be realized by using the built-in FISH program of FLAC3D. The algorithm solution flow is shown in Figure 3.

Finite element analysis of the slope safety coefficient numerical difference method has many calculation methods, such as analysis of circular sliding surface Bishop method, Swedish slice method and analysis of arbitrary sliding surface Sarma method. The Bishop method is selected to calculate the safety factor. In the safety factor, the radius of the sliding surface and the center of the circle should be assumed, and the dangerous sliding surface and the minimum safety factor are found by many iterative calculations. Its calculation is shown in formula (1) and formula (2).

$$
\begin{gathered}
F_{S}=\frac{1 / m_{a_{i}} \sum\left[c_{j} b_{i}+\left(W_{i}+u_{i} b_{i}\right) \tan \phi_{i}\right]}{\sum\left[w_{j} \sin a_{i}+1 / R \sum Q_{i} e_{i}\right]} \\
m_{a_{i}}=\cos a_{i}+\frac{\tan \phi_{i} \sin a_{i}}{F_{S}}
\end{gathered}
$$

In the above formula, $a_{i}$ is the slope angle at the bottom of the soil strip. $h_{i}$ is the height of the soil strip. $b_{i}$ is the width of the soil strip. $W_{i}$ is the self-weight of the soil. $Q_{i}$ is a horizontal force. $u_{i}$ is the pore water pressure at the bottom of the soil strip. $\mathrm{R}$ is the radius of the arc. $e_{i}$ is the force arm of the horizontal force of the earth bar against the arc center. $c_{j}$ is the effective cohesive force of the soil at the bottom of the soil strip. $\phi_{i}$ is the effective internal friction angle of the soil at the bottom of the soil strip. $F_{S}$ is the safety factor of the sliding surface. 


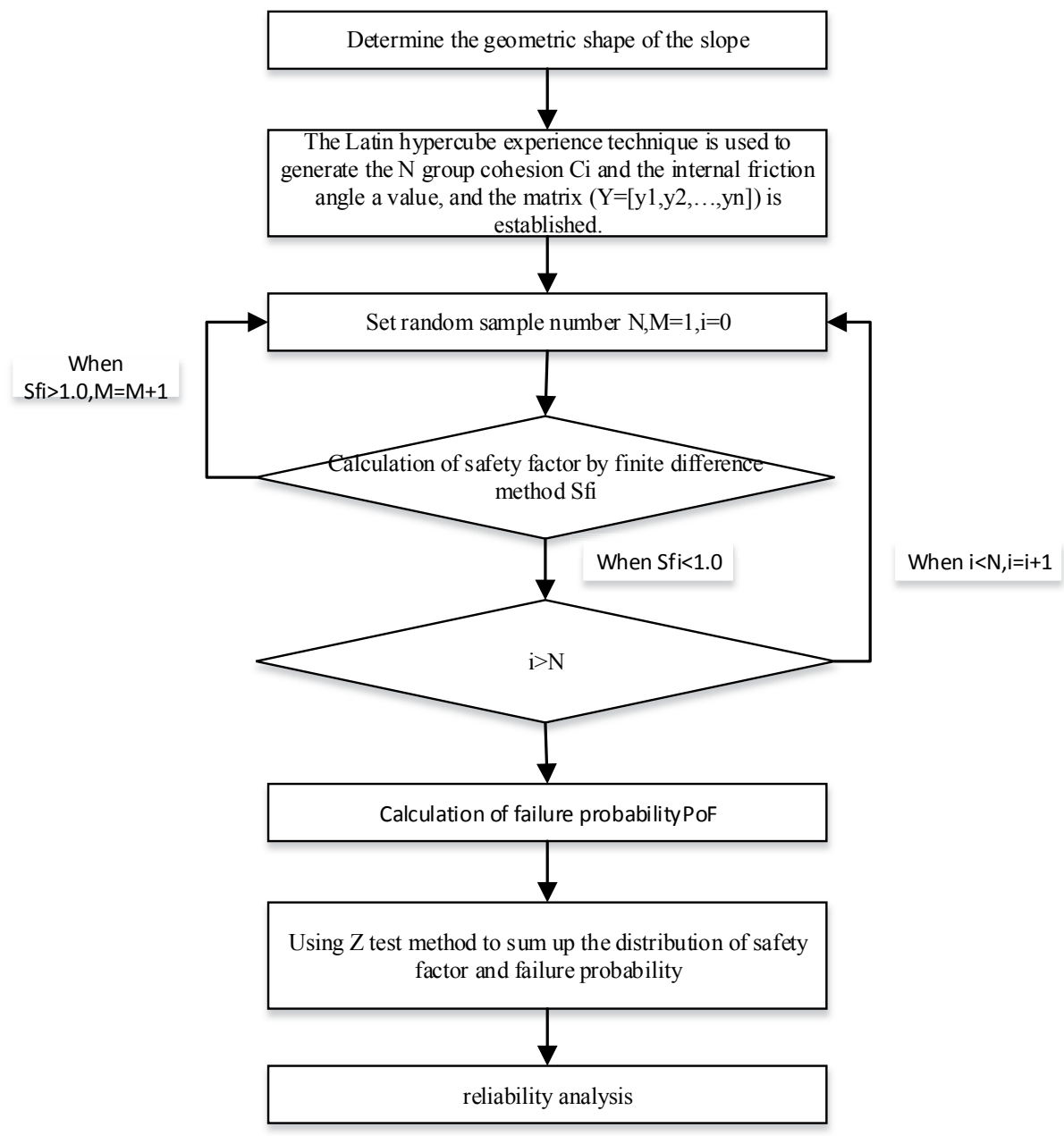

Fig. 3. Flow chart of reliability calculation

\section{$4 \quad$ Result Analysis and Discussion}

The physical and mechanical properties of the 10 samples were obtained by LHSMCS sampling, as shown in Table 1. First, the grid model is set up to fix the bottom and the boundary. The iterative calculation process can be completed by the fish program in FLAC3D.

Matlab7.11.0 (R2012b) is used for the curve fitting of the data in table 6.2, as shown in Figure 4.

The LHSMCS method is used to calculate the safety factor of the $\mathrm{N}=100$ and $\mathrm{N}=1000$ samples. The calculation results are shown in Figure 5 and Figure 6. 
Table 1. Mechanical properties of rock mass

\begin{tabular}{|c|c|c|c|c|}
\hline Number & Dead weight $\left(\mathbf{k g} / \mathbf{m}^{\mathbf{3}}\right)$ & Cohesive strength (kpa) & $\begin{array}{c}\text { Internal friction } \\
\text { angle }(\mathbf{})\end{array}$ & $\begin{array}{c}\text { Safety factor } \\
\text { (Mpa) }\end{array}$ \\
\hline 1 & 2200 & 99 & 31.84 & 1.37 \\
\hline 2 & 3700 & 61 & 46.70 & 0.73 \\
\hline 3 & 2560 & 189 & 41.90 & 1.96 \\
\hline 4 & 2200 & 26 & 13.90 & 1.57 \\
\hline 5 & 2400 & 120 & 34.42 & 1.75 \\
\hline 6 & 2750 & 169 & 37.97 & 1.22 \\
\hline 7 & 2790 & 202 & 41.34 & 2.12 \\
\hline 8 & 2570 & 70 & 26.63 & 2.16 \\
\hline 9 & 3710 & 111 & 49.99 & 1.47 \\
\hline 10 & 2360 & 497 & 50.20 & 1.59 \\
\hline
\end{tabular}

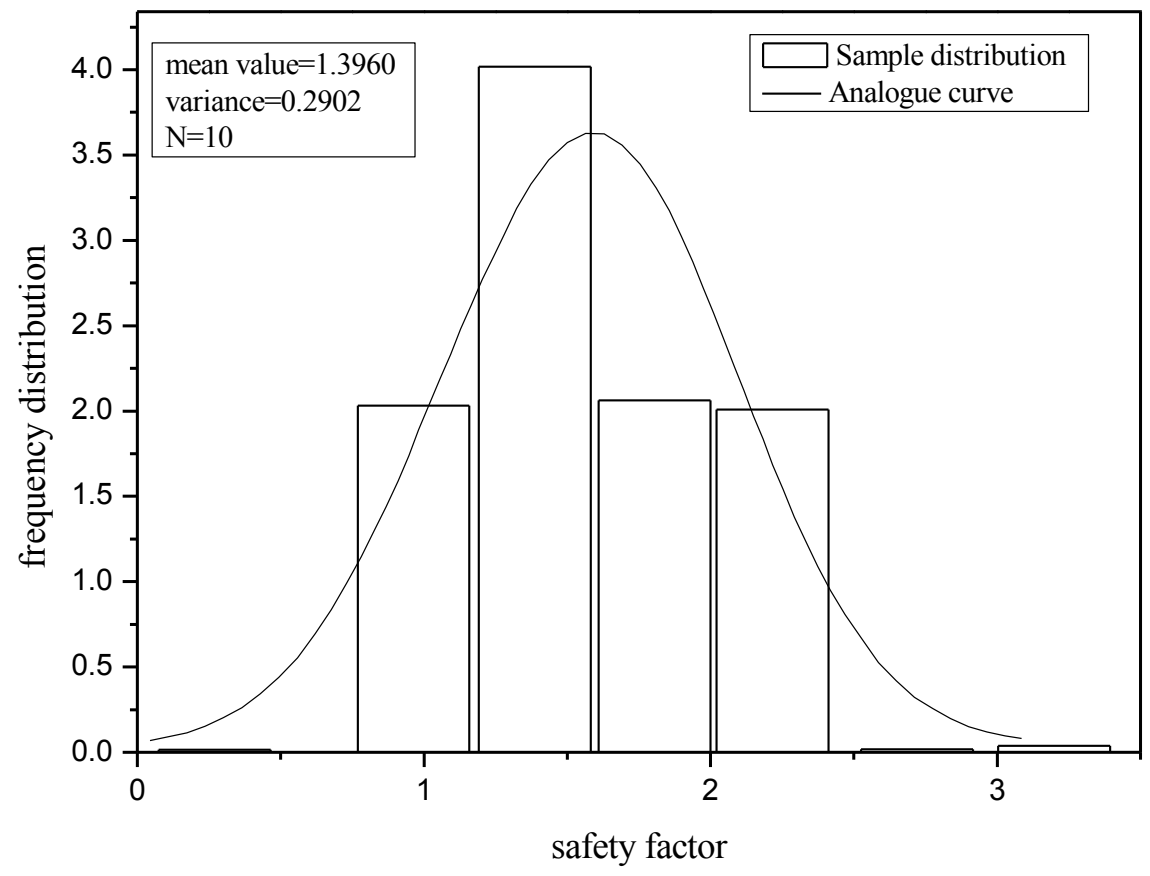

Fig. 4. $\mathrm{N}=10$ safety coefficient frequency histogram 


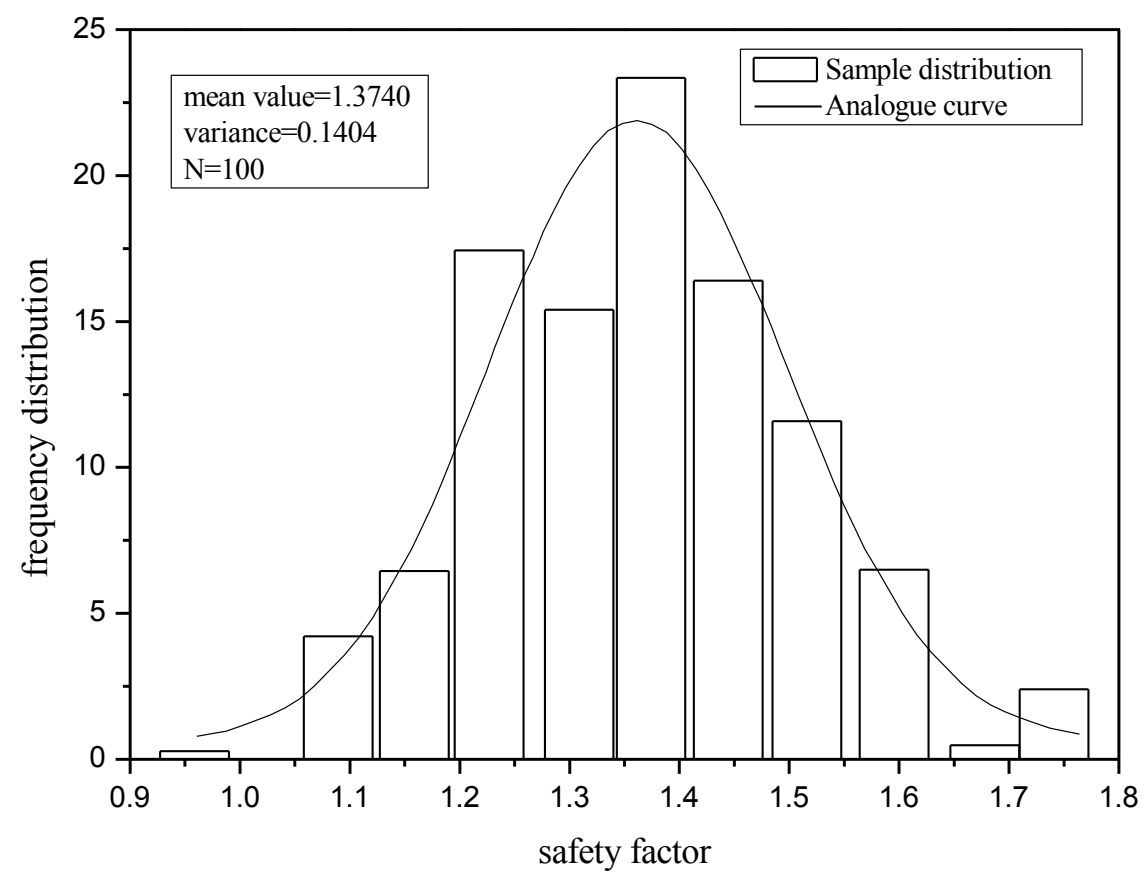

Fig. 5. $\mathrm{N}=100$ safety coefficient frequency histogram

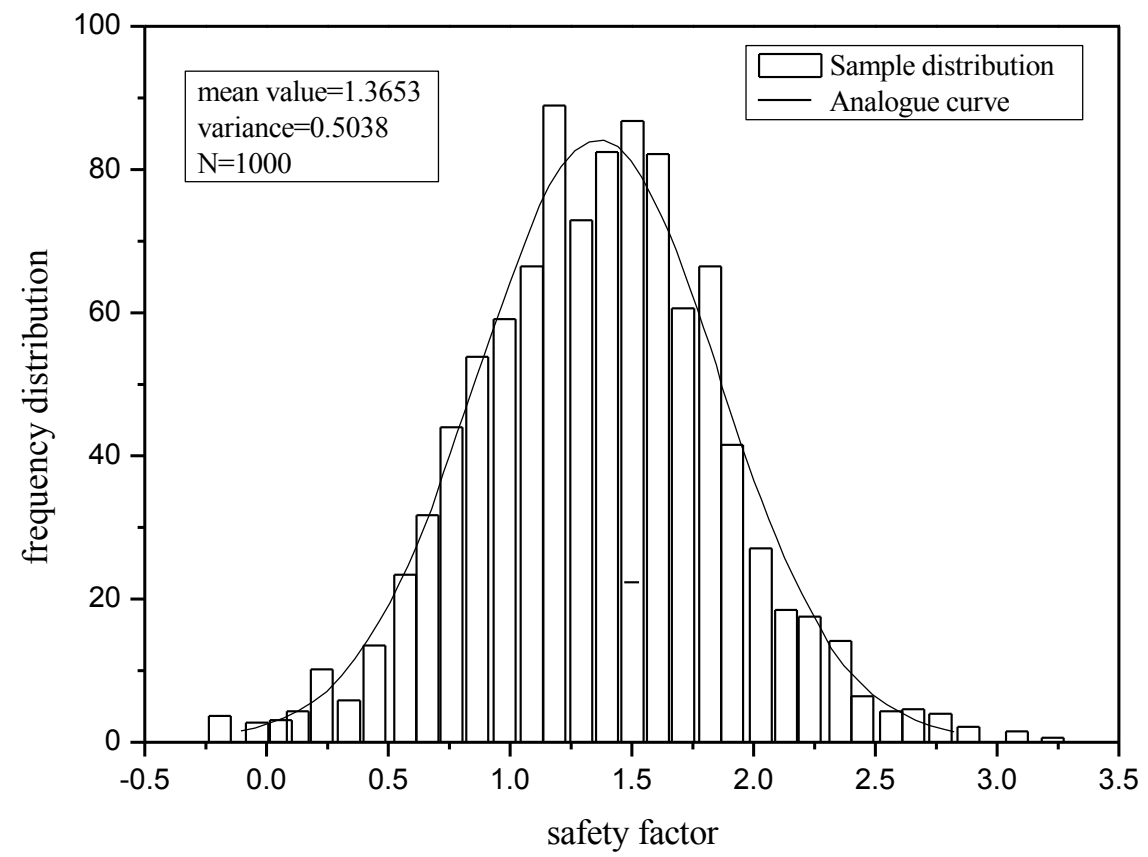

Fig. 6. $N=1000$ safety coefficient frequency histogram 
From the safety factor frequency histogram, when the number of samples is large enough, the safety factor follows a normal distribution. The mean and standard deviation of the normal distribution are shown in Table 2.

Table 2. The probability of safety factor statistics

\begin{tabular}{|c|c|c|c|c|}
\hline $\begin{array}{c}\text { Number of simula- } \\
\text { tions N }\end{array}$ & Failure times M & $\begin{array}{c}\text { Probability of } \\
\text { failure }\end{array}$ & Mean $\boldsymbol{\mu}$ & Variance $\boldsymbol{a}$ \\
\hline 10 & 1 & 0.10 & 1.3960 & 0.2902 \\
\hline 100 & 4 & 0.04 & 1.3740 & 0.1404 \\
\hline 1000 & 48 & 0.048 & 1.3653 & 0.5038 \\
\hline
\end{tabular}

It can be seen from Table 3, when the number of samples increases gradually, the average value of samples decreases from 1.3960 to 1.3653 . The probability of failure also tends to be a steady value as the number of samples increases. When the number of samples is large enough, the safety factor and failure probability are in a stable state. It does not change much anymore. The experimental results coincide with the large number theorem. When the number of samples $\mathrm{N}$ tends to infinity, the failure probability $P_{f}$ gradually converges to the probability $\mathrm{P}$.

The $\mathrm{Z}$ test method was used to test the reliability level of the safety factor. The stability of the slope is influenced by many uncertain parameters. When there is a significant difference between a sample parameter $\mu$ and the overall mean value $\mu_{0}$, a significant test of the parameter is needed. For example, because of the anisotropy of rock mechanical properties, the hypothesis testing method can be used to analyze the probability of mine slope stability affected by uncertain factors. There are many kinds of statistical methods that can be used to assume the test. The $\mathrm{Z}$ test method was selected. $H_{0}$ is a proposed hypothesis. $H_{1}$ is an alternative hypothesis. Its definition is as follows:

$$
H_{0}: \mu=\mu_{0} \vee \mu \neq \mu_{0}
$$

The test statistics are as follows:

$$
Z_{H}=\frac{\mu-\mu_{0}}{\sigma / \sqrt{n}}
$$

In the formula, $\sigma$ is the standard deviation, $n$ is the sample number, and $\mu_{0}$ is the overall mean. According to the central limit theorem, when $n$ is large enough, its mean value and variance follow the standard normal distribution. When the difference between the sample value $\mu$ of the failure probability and the value of the overall average $\mu_{0}$ is larger, the statistic $Z_{H}$ gradually increases. The absolute value of $Z_{H}$ is also used as a measure of the probability of failure. 
As can be seen from Table $2, \mu=1.3653, \mathrm{~s}=0.5038$. The reliability theory is used to evaluate the stability of the structure. In recent years, the development of the slope is very rapid, especially in the slope stability evaluation. Generally, the safety factor of the slope is calculated by the reliability theory center point method. The failure probability $\mathrm{P}_{f}$ is more than 0.07 . When the probability $\mathrm{P}$ is less than 0.93 , the $\beta$ value at this time is about 1.65 (the calculation of different examples may be different). When the reliability index of the rock slope is less than the above two values, the system will send out a warning to shorten the observation period and increase the observation frequency.

\section{Conclusions}

The data collection, data transmission, data management and data analysis in the whole process of slope monitoring are studied. The following main conclusions are drawn.

Firstly, the stability of the slope is influenced by many factors. In order to collect information that affects the stability of slope, a multi-parameter and multi-device monitoring system based on Internet of Things is proposed. The key technology is introduced.

Secondly, the monitoring cycle of the slope monitoring project is long, so it requires low real-time data. However, because of the particularity of monitoring environment, it has high requirements for energy saving, scalability and robustness of wireless transmission network.

Thirdly, the effectiveness and accuracy of the monitoring data have a major role in predicting the stability of the slope. Therefore, the data must be properly managed and classified. The key to the data management process is to extract useful data from the massive monitoring data, which is useful to the prediction process. The information fusion technology, such as Kalman filtering, trend fitting and linear correlation analysis, can effectively solve this problem.

Fourthly, each prediction criterion theory has different emphasis on the change law of slope displacement. The reliability theory is applied to the stability analysis of the local slope and the section. The finite element method focuses more on the prediction of the stress distribution and displacement trend of the whole slope. The combination of several forecasting theories can predict the stability of the slope more scientifically.

\section{References}

[1] Smethurst, J. A., Smith, A., Uhlemann, S., Wooff, C., Chambers, J., Hughes, P,\& Hughes, D. Current and future role of instrumentation and monitoring in the performance of transport infrastructure slopes. Quarterly Journal of Engineering Geology and Hydrogeology, 2017, vol. 50, pp. 271-286. https://doi.org/10.1144/qjegh2016-080

[2] Srivastava, A. Spatial variability modelling of geotechnical parameters and stability of highly weathered rock slope. Indian Geotechnical Journal, 2012, vol. 42, pp. 179-185. https://doi.org/10.1007/s40098-012-0016-4 
[3] Ulusay, R., Ekmekci, M., Tuncay, E., \& Hasancebi, N. Improvement of slope stability based on integrated geotechnical evaluations and hydrogeological conceptualisation at a lignite open pit. Engineering Geology, 2014, vol. 181, pp. 261-280. https://doi.org/10.1016/j.enggeo.2014.08.005

[4] Aly, H., Elmogy, M., \& Barakat, S. Big Data on Internet of Things: Applications, Architecture, Technologies, Techniques, and Future Directions. Int. J. Comput. Sci. Eng, 2015, vol. 4, pp. 300-313.

[5] Du, W., \& Wang, G. Fully probabilistic seismic displacement analysis of spatially distributed slopes using spatially correlated vector intensity measures. Earthquake Engineering \& Structural Dynamics, 2014, vol. 43(5), pp. 661-679. https://doi.org/10.1002/eqe.2365

[6] Lin, M. S., Leu, J. S., Li, K. H., \& Wu, J. L. C. Zigbee-based internet of things in 3D terrains. Computers \& Electrical Engineering, 2013, vol. 39(6), pp. 1667-1683. https://doi.org/10.1016/j.compeleceng.2012.09.018

[7] Rui, J. Research on Security Issues of Geological Disaster Warning System. Information Security and Technology, 2013, vol. 8, pp. 032.

[8] Guo, Y., Liu, H., \& Chai, Y. The embedding convergence of smart cities and tourism internet of things in China: An advance perspective. Advances in Hospitality and Tourism Research (AHTR), 2014, vol. 2(1), pp. 54-69.

[9] Sun, E., Zhang, X., \& Li, Z. The internet of things (IOT) and cloud computing (CC) based tailings dam monitoring and pre-alarm system in mines. Safety science,2012, vol. 50(4), pp. 811-815. https://doi.org/10.1016/j.ssci.2011.08.028

[10] Zheng, Z. C., Xu, W. Y., Xu, F., \& Liu, Z. B. Forecasting of slope displacement based on PSO-LSSVM with mixed kernel. Rock Soil Mech, 2012, vol. 33(5), pp. 1421-1426.

[11] Li, Q. Y., Xu, J., Wang, W. H., \& Fan, Z. P. Slope displacement prediction based on morphological filtering. Journal of Central South University, 2013, vol. 20(6), pp. 1724-1730. https://doi.org/10.1007/s11771-013-1665-x

\section{$7 \quad$ Author}

Xiaobing Hou is with Anyang Institute of Technology, Anyang, China.

Article submitted 07 February 2018. Resubmitted 18 March 2018. Final acceptance 04 April 2018. Final version published as submitted by the authors. 